\title{
The relationship between sleep quality and perceived social support with
}

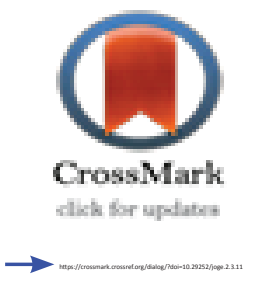

\author{
loneliness in elderly men \\ Mirzaei $\mathrm{F}^{1}$, *Khodabakhshi-Koolaee $\mathrm{A}^{2}$
}

1- MSc of Counseling, Department of Counseling, Islamic Azad University, Science and Research Branch, Tehran, Iran.

2- Assistant Professor, Psychology and Education Department, Faculty of Humanities, Khatam University, Tehran, Iran (Correspondence Author)

E-mail: a.khodabakhshid@khatam.ac.ir

\section{Abstract}

Introduction: ageing period affect on variety of psychological and social factors like; social support, loneliness and quality of sleep. The main objective of this study was to assess the relationship between sleep quality and perceived social support with loneliness in elderly men.

Method: The current study is descriptive research. 100 elderly men between 65 to 75 years old were selected by Available sampling method through district number 20 and the Jahandidegan centers of Tehran Municipality by 2015-2016. Data collection tools included mental state examination (MMSE), Screening subjects and Pittsburgh Sleep Quality Index (PSQI), loneliness questionnaire (UCLA) and perceived social support questionnaire were Zymt (MSPSS). In order to analyze data from tables descriptive statistics, Pearson correlation and ,stepwise regression were used.

Results: The results showed that there was a negative significant relationship between sleep quality and loneliness with perceived social support. Social protection alone is able to predict loneliness in elderly men and $58 \%$ of its variance was explained through it $(p<0 / 01)$. In the second model, social support and quality sleep together have been able to predict 61 percent of the variance of loneliness $(\mathrm{p}<0 / 01)$.

Conclusion: Attention to the quality of life, loneliness, and perceived social support among elderly men could be useful. The findings of this study focus on the role of social support in the elderly health care. Therefore, it is suggested to the psychologists and counselors to develop programs based on promotion of social support and prevention the loneliness and isolation in elderly men.

Keywords: Sleep Quality, Perceived social support, Loneliness, Elderly.

Received: 28/12/2017 Accepted: 24/02/2018

\begin{tabular}{|l|l|}
\hline \multicolumn{3}{|c|}{ Access this article online } \\
\hline \multicolumn{2}{|c|}{$|l|$} \\
\hline
\end{tabular}




\section{ارتباط بين كيفيت خواب و حمايت اجتماعى ادر اك شده با احساس تنهايى در سالمندان مرد}

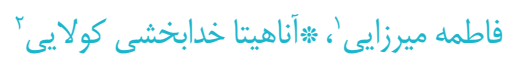

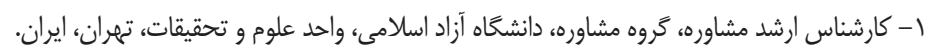

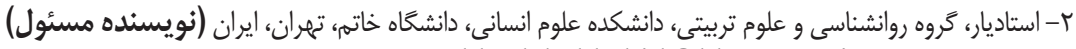

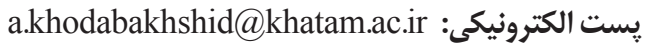

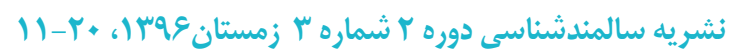

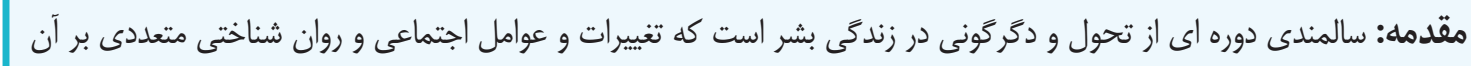

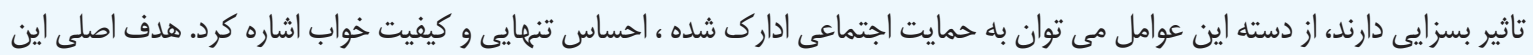

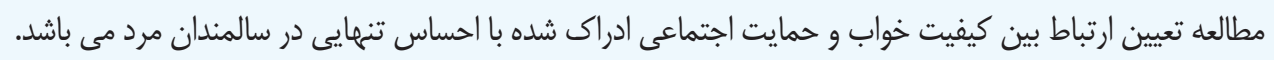

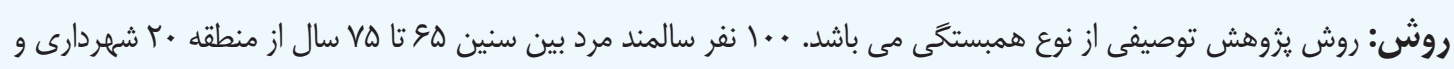

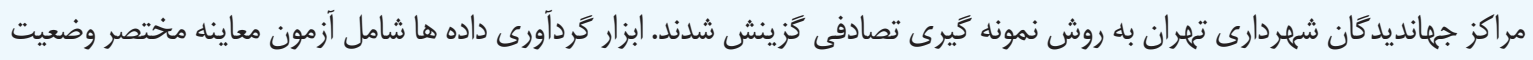

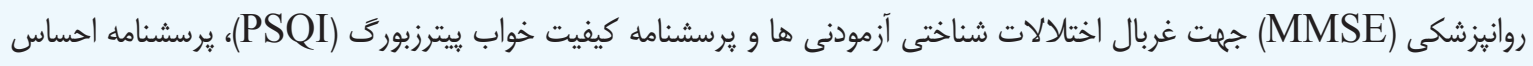

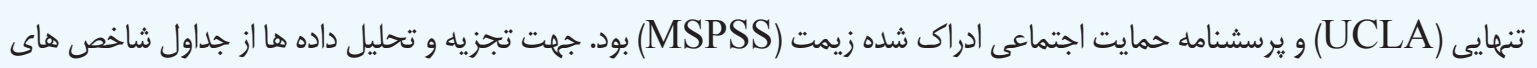

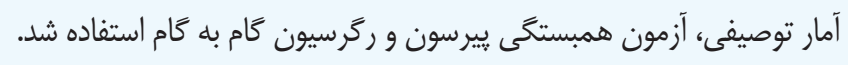

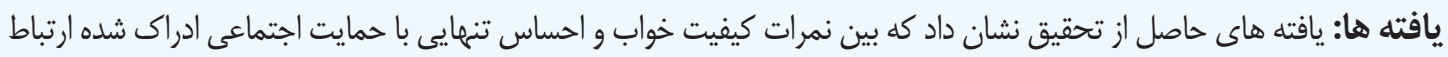

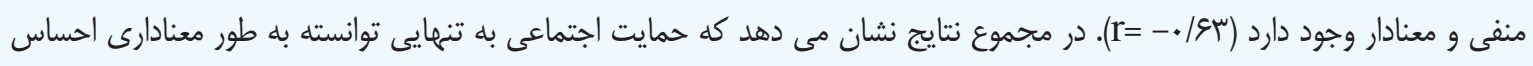

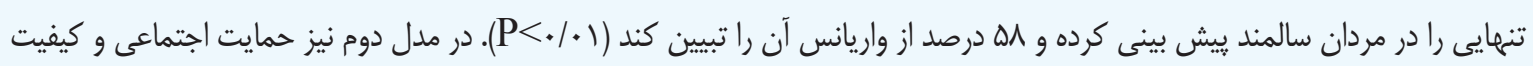

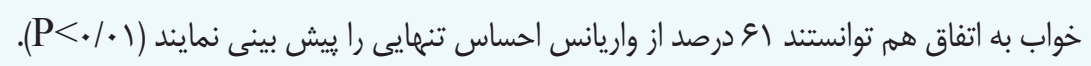

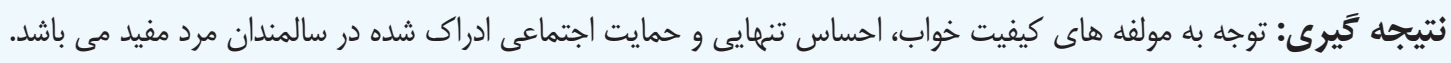

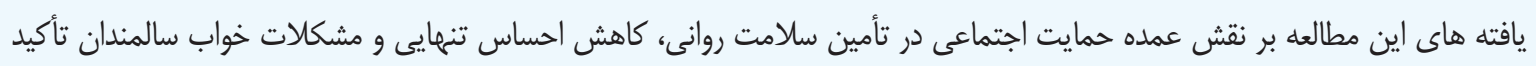

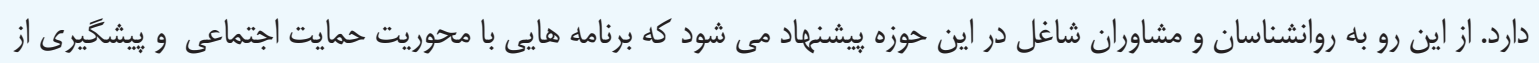
انزوا جهت ارتقاى سلامت روانى سالمندان تدوين كنند.

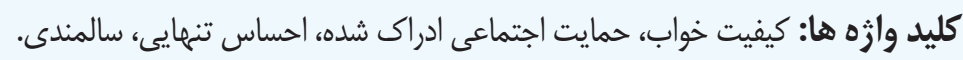

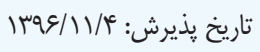

تاريخ دريافت: / / وهسا 


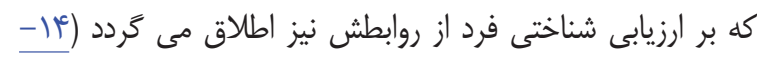

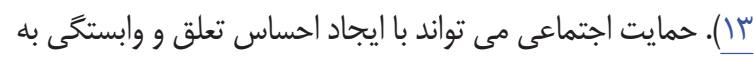

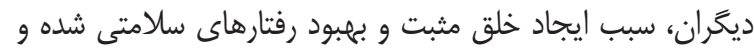

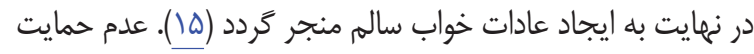

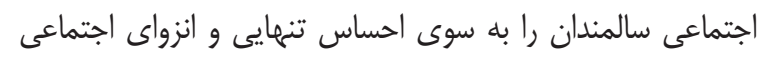

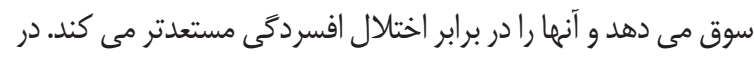
يزوهشى كه در جامعه سالمندان آمريكا انجام شد، نتايج نشان داد كه إنها

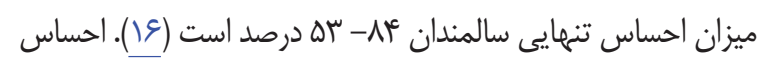

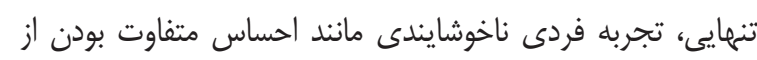

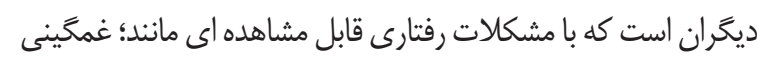

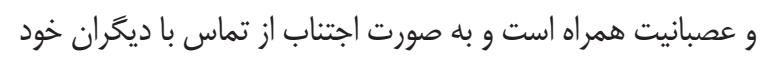
را آشكار مى سازد (IV) روانشناسان احساس تنهايى را عدم هماهنكَى ميان سطحى از

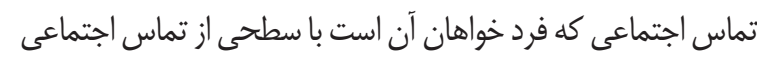

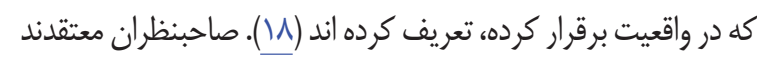

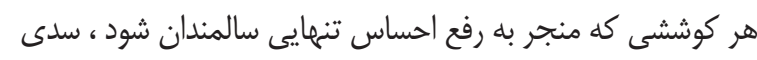

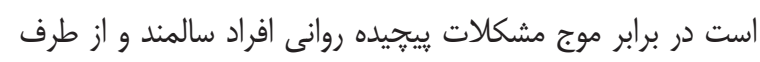

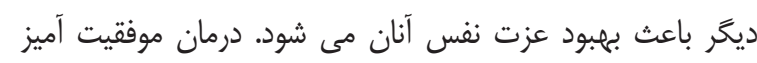

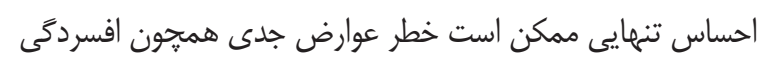

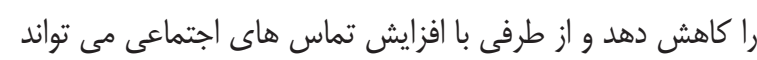

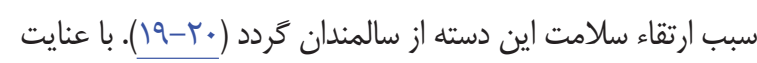

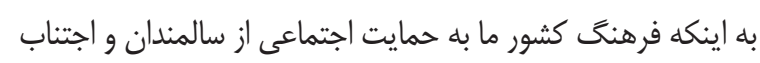

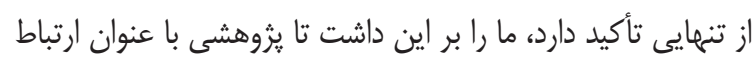

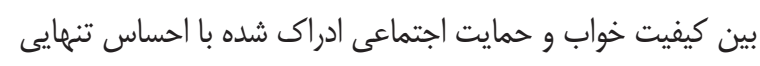

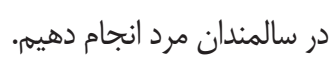

\section{ورش مطالعه}

يزوهش حاضر، مطالعه اى توصيفى از نوع همبستكى روالى

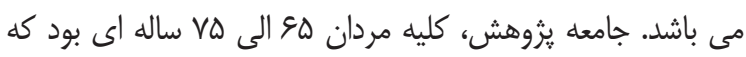

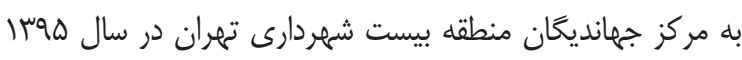

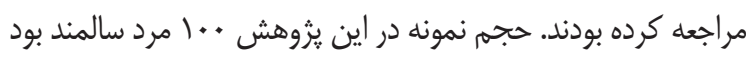

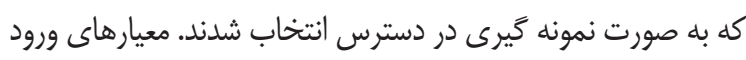
شامل تمايل به همكارى جهت شركت در انجام يُوهش، توانايى دئ خواندن و نوشتن، عدم وجود بيماريهاى جسمى، عدم اخدام اختلالات

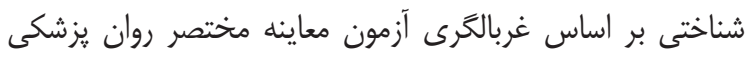
(M.M.S.E) خواندن و نوشتن بود. همجنين سالمندانى كه هر گَونه بيماريهاى جسمى حاد به تشخيص يزشك داشتند و همزمان با اين مطالعه در هod:o

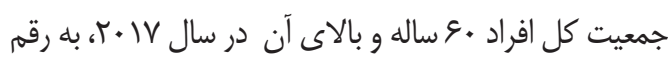

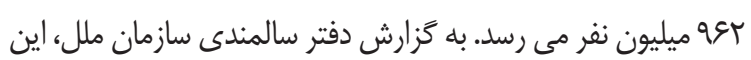
أمار بالغ بر دو برابر جمعيت سالمندان در سال • •19 19 ميلادى است. برآوردها نشان مى دهد كه تا سال •ه + ج جهان با جمعيت دو ميليارد

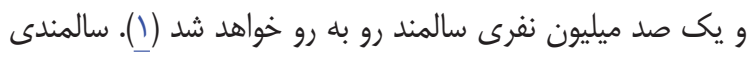

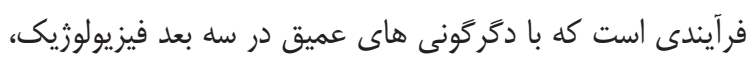

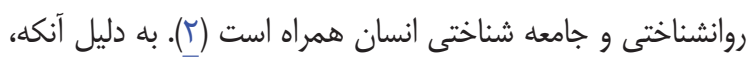

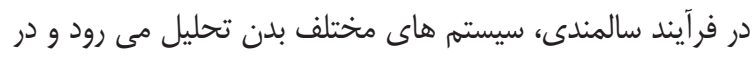

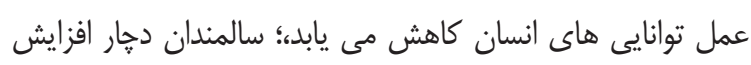

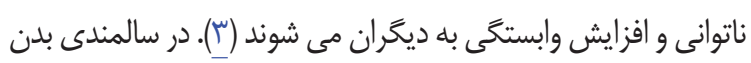

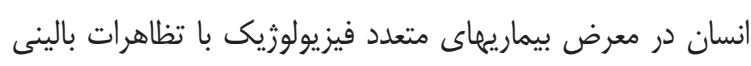
از جمله بيماريهاى قلبى و عروقى، افسردَّى، فراموشى و اختلال

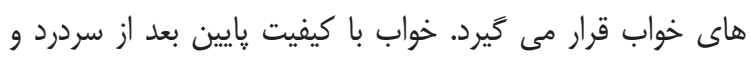

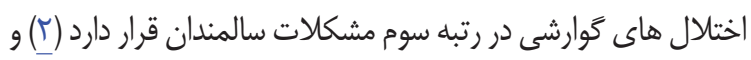

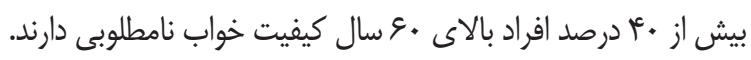

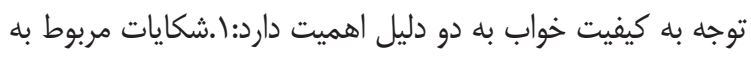

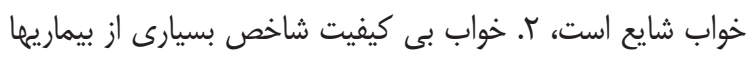

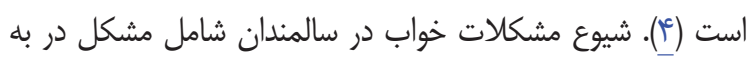

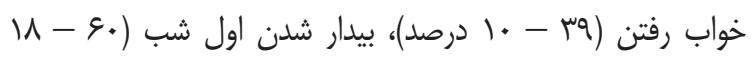

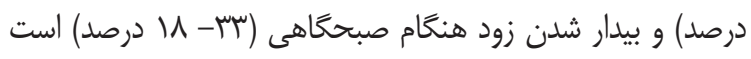

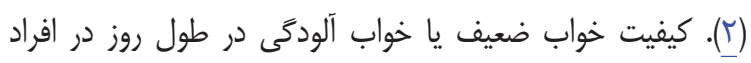

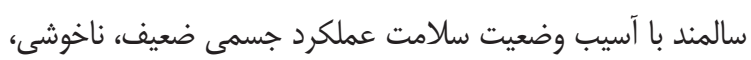

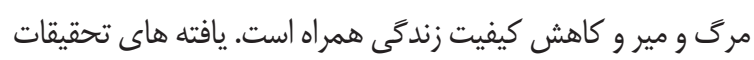

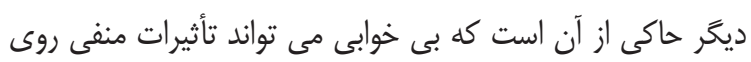

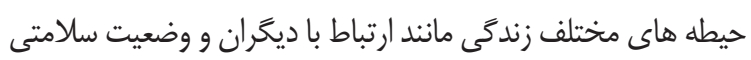

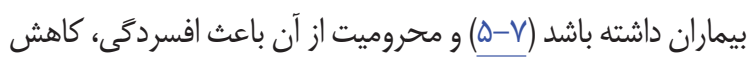

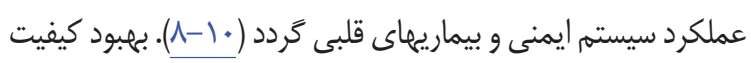

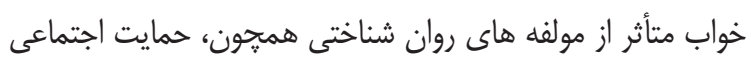

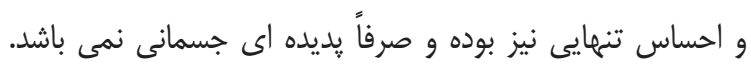
يزوهش ها نشان مى دهند كه، ارتقاى كيفيت روابط اجتماعى و

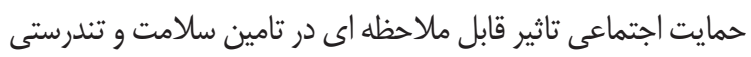

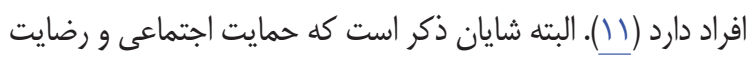

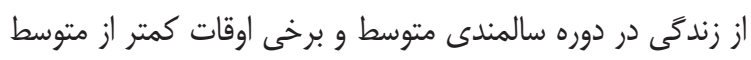

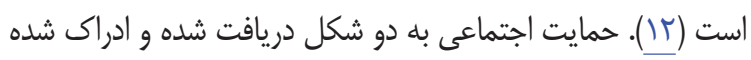

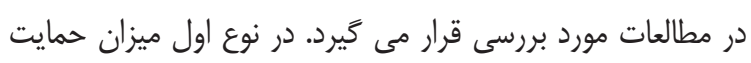

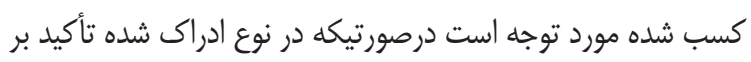

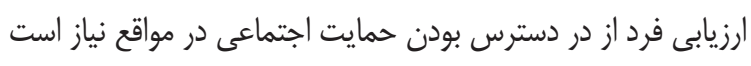


ليكرت هفت درجه اى از كاملاً موافق (V) تا كاملاً مخالف (ا) درجه اي اندازه كيرى كرديد. سرانجام نمره نهايى كسب شده از اين مقياس

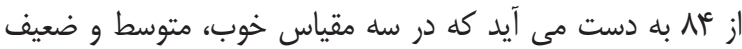

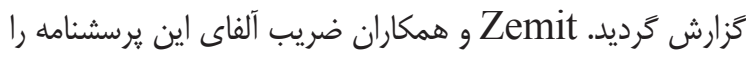

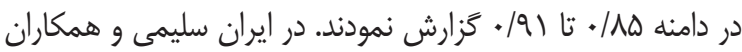
روايى و پِاياى اين مقياس را مورد بررسى قرار دادند كه در مطالعه

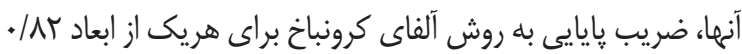

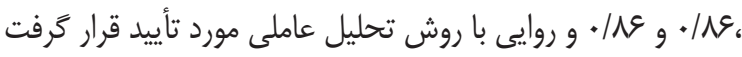

جهت سنجش از يرسشنامه احساس تنهايى دانشخاه كاليفرنيا

نسخه سوم Revised at University of California تُ Los Angles Loneliness Scale (UCLA تنهايى متداول فرد را كه در روابط بين فردى خود تجربه مى كند، استفاده شد. اين آزمون به عنوان اولين آزمون احساس تنهايى در درد

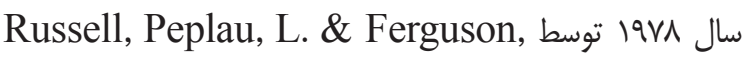
ساخته شد.اين مقياس • T سوال است كه براساس طيف جهار M.L درجه اى ليكرت نمره كذارى مى شود و داراى ده جمله مثبت و ده

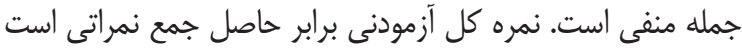

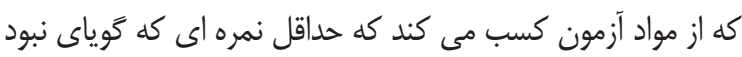
احساس تنهايى است • ب و حداكثر نمره •1 است و ميانكَين آزمون

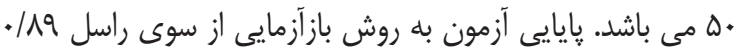
كزارش شده است و ضريب آلفاى كرونباخ براى كل مقياس (9)/.

$$
\text { كزارش شد (1).TV). }
$$

يس از اخذ معرفى نامه از سوى دانشعاه و با حضور در مركز

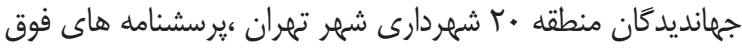
در بين سالمندان مراجعه كننده توزيع شد و پِ از تكميل آن، افرادى

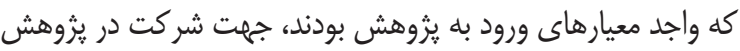

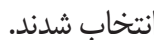
در نهايت تجزيه و تحليل داده ها، با استفاده از ضريب همبستخى ييرسون، تحليل رگرسيون گام به كام و نرم افزار

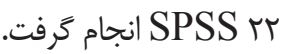

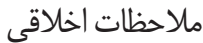

جهت رعايت ملاحظات اخلاقى ضمن توضيح اهداف يثوهش ماحش

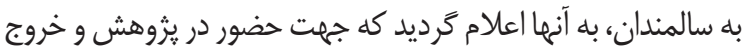
از آن اختيار تام داشته و در صورت تمايل نتايج آزمون در اختيار آنها

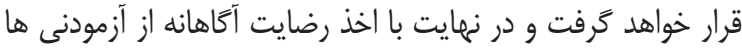
و اعلام محرمانحى يرسشنامه ها، آزمودنى ها يرسشنامه ها را با بدون ذكر نام و با استفاده از كد تكميل كردند.
جلسات روانشناسى شركت كرده بودند از مطالعه خارج شدند. جهت سنجش وضعيت شناختى از مقياس معاينه مختصر M.M.S.E) Mini Mental Status) وضعيت ذهنى Marshal استفاده شد كه در سال lava توسط Examination F. Folstein انتخاب، اززيابى حوزه هاى مختلف شناختى و قابليت به خاطر سبردن

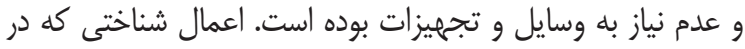
اين آزمون مورد ارزيابى قرار مى گيرد عبارت از حافظه جهت يابى، ثبت، توجه و محاسبه، حافظه اخير، عملكردهاى مختلف زبانى و تفكر فضايى است. ياسخ به هر سوال، صحيح يا نادرست بوده و امتياز كلى

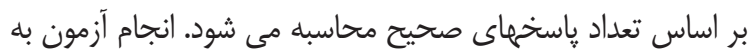

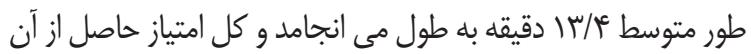
• بامتياز است كه بر اساس كتب مرجع نمره كمتر از ها به احتمال

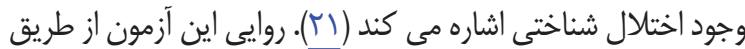

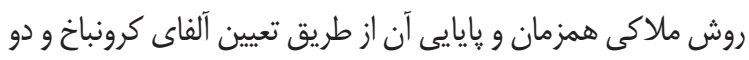

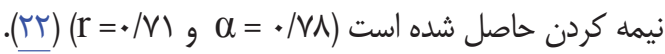
جهت سنجش كيفيت خواب از Pittsburgh Sleep Quality Index(PSQI خودگزارشى است و كيفيت خواب را مى سنجد و بهترين ابزار مناسب براى اندازه كيرى كيفيت خواب در افراد سالمند است (ع). اين يرسشنامه يك يرسشنامه استاندارد و داراى \ل سوال است. اين سوالات در V جزء كه شامل كيفيت خواب، تأخير در به خواب رفتن، مدت زمان خواب بودن، كارائى و مؤثر بودن خواب بيمار، مصرف داروهاى خواب آور و عملكرد نامناسب در طول روز هستند، طبقه بونه بندى مى شود. امتياز هر سوال بين • تا ب امتياز است و امتياز هر جزء نيز حداكثر س مى باشد. مجموع ميانكَين نمرات اين ل جزء، نمره

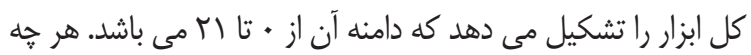

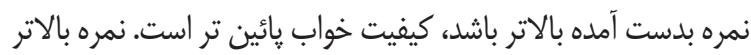

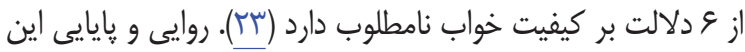
يرسشنامه در ايران نيز تأييد شده است. به طوريكه در يزوهش حسن

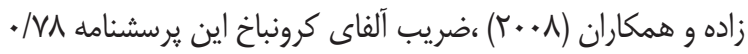

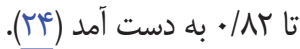
جulti- جهت سنجش حمايت اجتماعى ادراك شده از Dimensional Perceived Social Support Zimet استفاده شد. اين مقياس در سال $19 M$ الوسط (MSPSS و همكاران ساخته شد (ه) . اين مقياس rا گَويه دارد كه درك افراد را از حمايت اجتماعى دريافت شده توسط سه منبع خانواده، دوستان و

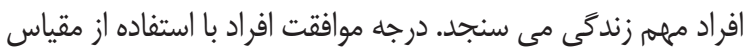


دو و سه فرزند بوده و سرانجام از لحاظ وضعيت تأهل بو درصد افراد شركت كننده متأهل بوده و ^ץ درصد از آنها نيز همسر انشان در زمان انجام يزوهش فوت شده بودند، اما هيج مجردى در بين شركت كنندگان وجود نداشت. نتايج شاخص هاى توصيفى مربوط به كيفيت خواب، حمايت اجتماعى ادراك شده و احساس تنهايى نشان داده شده است (جدول ()).

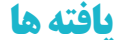

ويزگَيهاى جمعيت شناختى شركت كنندًان در يزوهش حاضر به شرح زير مى باشد: از لحاظ سنى شركت كنندكان بين سن

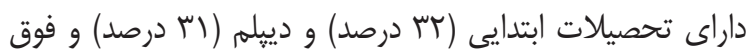
دييلهم و بالاتر (TV درصد) بودند. از لحاظ تعداد فرزندان، عس درصد از شركت كنندگان يك فرزند را داشته و أبه درصد از آنها داراى

\begin{tabular}{|c|c|c|c|c|c|}
\hline انحراف معيار & ميانغين & حداكثر & حمره & زير مقياسها & متغيرها \\
\hline . / & $1 / .9$ & r & . & كيفيت ذهنى خواب & \\
\hline $1 / 1$ & $1 / V^{4}$ & $\Delta$ & • & تاخير در به خواب رفتن & \\
\hline . & $1 / 9$ & r & • & مدت زمان خواب & \\
\hline$\cdot / \Delta F$ & $\cdot / 4$ & r & • & ميزان بازدهى خواب & ك. \\
\hline$\cdot / \Delta V$ & $1 / 4$ & r & · & اختلالات خواب & تيعيت حواب \\
\hline $1 / 48$ & $1 / 10$ & r & • & داروى خواب آور & \\
\hline$\cdot / 90$ & $\cdot / 91$ & r & • & اختالالات عملكردى روزانه & \\
\hline$r / \pi f$ & $N \cdot 1$ & 19 & $r$ & 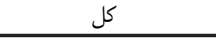 & \\
\hline S/QT & $r \cdot / \Delta T$ & rA & 8 & 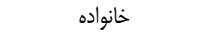 & \\
\hline s/VQ & $|V / \mu|$ & rA & r & دوستان & حيطت لجتوب \\
\hline ( & $r \cdot / 11$ & rA & $\wedge$ & افراد مهم & فمايع اجبما \\
\hline IV/OT & $\Delta \wedge$ & $\Lambda \mathrm{f}$ & re & كل - مل - مل & \\
\hline $\mid Y / 9 V$ & $\mid \mathrm{F} / \cdot \mathrm{r}$ & $8 \wedge$ & r. & نمره كل & احساس تنهايى \\
\hline
\end{tabular}

نتايج ماتريس همبستخى ييرسون بين متغيرهاى مورد مطالعه مقياس هاى در (جدول r) نمايش داده شده است. كيفيت خواب و خرده مقياس هاى آن و حمايت اجتماعى و خرده جدول r: نتايج ضرايب همبستخى ييرسون بين كيفيت خواب و حمايت اجتماعى ادراك شده

\begin{tabular}{|c|c|c|c|c|c|c|c|c|c|c|c|c|c|}
\hline ir & 11 & 1. & 9 & $\Lambda$ & $v$ & 9 & $\Delta$ & i & r & $r$ & 1 & متغيرها & \\
\hline 1 & $\begin{array}{c}1 \\
\cdot / V^{\text {絭楼 }}\end{array}$ & $\begin{array}{c}1 \\
\cdot / \Delta r \\
\cdot / V T * * \%\end{array}$ & $\begin{array}{c}1 \\
\cdot / V T \text { \%* } \\
\cdot|\Delta| * \\
\cdot \mid \Delta Y *\end{array}$ & 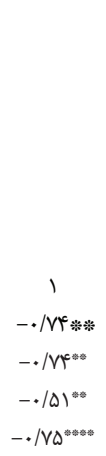 & $\begin{array}{c}1 \\
-\cdot / \Delta \cdot r \\
-\cdot / \Delta \mid \cdots * \\
-\cdot / \Delta r^{* *} \\
-\cdot / r r^{* *} \\
-\cdot / \Delta r^{* *}\end{array}$ & 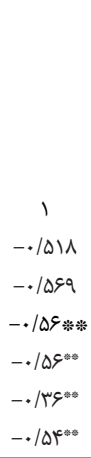 & 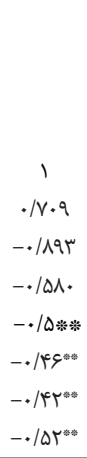 & 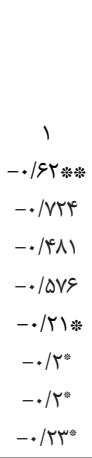 & 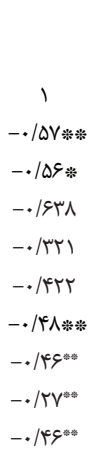 & 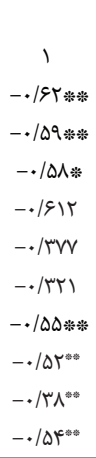 & 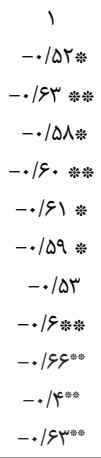 & 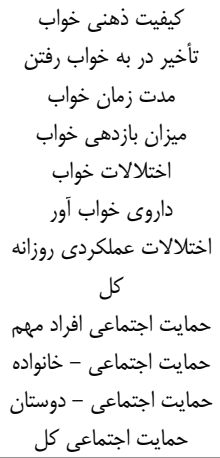 & $\begin{array}{l}1 \\
r \\
r \\
r \\
0 \\
8 \\
v \\
1 \\
9 \\
1 . \\
11 \\
1 r\end{array}$ \\
\hline
\end{tabular}

$\mathrm{P}<0.05 * * \mathrm{P}<0.01$ *

خواب استفاده شده در اين يزوهش، نمرات بالا حاكى از اختلال خواب و نمرات يايين نشان دهنده كيفيت خواب بالاتر است. حال با تبا توجه به اينكه رابطه بين تك تكى متغيرها با يكديخر تاييد شد، براى

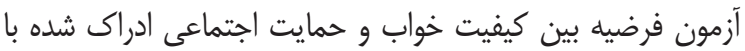
احساس تنهايى در مردان سالمند رابطه وجود دارد، از روش تحليل
با توجه به ضرايب همبستخى ارائه شده در (جدول r) ملاحظه مى شود كه بين كيفيت خواب و حمايت اجتماعى ادراك شده در

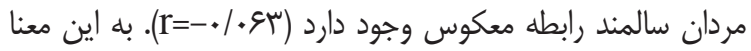
كه با افزايش ميزان حمايت اجتماعى ادراك شده سالمندان، نمره آنها در يرسشنامه كيفيت خواب كاهش مى يابد كه در يرسشنامه كيفيت 
به عنوان متغيرهاى ييش بين با هم وارد تحليل گَرديد كه نتايج آن

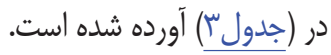

ركر سيون كام به كام استفاده شد. به اين ترتيب كه احساس تنهايى به عنوان متغير ملاك و نمرات كل حمايت اجتماعى و كيفيت خواب

\begin{tabular}{|c|c|c|c|c|c|c|c|c|c|c|}
\hline Sig & dfr & df & تغييرات & Rr Rغييرات & خطاى معيار & تعديل Rr شده & Rr & $\mathrm{R}$ & مدل & \\
\hline.$/ . .1$ & 91 & 1 & גז & $\cdot / \Delta \Lambda$ & $N / r$ & $\cdot / \Delta \Lambda$ &.$/ \Delta \Lambda$ & . IVS & حمايت اجتماعى & 1 \\
\hline.$/ \cdot 1$ & १४ & 1 & $V / q$ & . r & $V / q$ &.$|9|$ &.$|9|$ & $\cdot / \mathrm{VA}$ & حمايت اجتماعى و كيفيت خواب & $r$ \\
\hline
\end{tabular}

بينى كند و هه درصد از واريانس آن را تبيين كند. در مدل دوم نيز

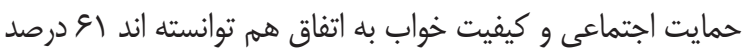
از واريانس احساس تنهايى را ييش بينى نمايند.
در (جدولّ)، دو مدل براى بيش بينى احساس تنهايى معنادار هستند. در مدل اول حمايت اجتماعى به تنهايى توانسته است به طور معنادارى احساس تنهايى را در مردان سالمند ييش

\begin{tabular}{|c|c|c|c|c|c|c|c|}
\hline Sig & $\mathrm{F}$ & ميانكين مجذورات & Df & مجموع مجذورات & منبع & مدل & \\
\hline.$/ . .1$ & 吾 & $\begin{array}{l}q \mu . . \\
q V / \mu\end{array}$ & $\begin{array}{c}1 \\
91 \\
99\end{array}$ & $\begin{array}{l}9 \% . . \\
9090 \\
10190\end{array}$ & باقيمانده & حمايت اجتماعى & 1 \\
\hline $.1 . .1$ & $W / q$ & $\begin{array}{l}\text { rAM } \\
\text { gr/A }\end{array}$ & $\begin{array}{l}r \\
9 r \\
99\end{array}$ & $\begin{array}{l}9199 \\
9.99 \\
10190\end{array}$ & باقيمانده & حمايت اجتماعى و كيفيت خواب & $r$ \\
\hline
\end{tabular}

اجتماعى به همراه كيفيت خواب هر دو در ييش بينى احساس تنهايى در جدول فوق نتايج تحليل واريانس نشان مى دهد كه

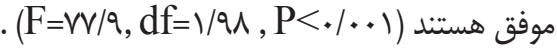

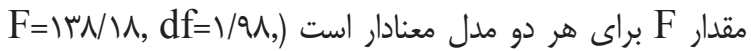

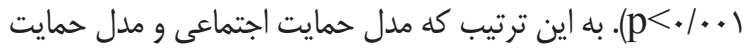
جدول ه: ضرايب ركرّسيونى ييش بينى احساس تنهايى از روى حمايت اجتماعى و كيفيت خواب

\begin{tabular}{|c|c|c|c|c|c|c|c|}
\hline \multirow{2}{*}{ Sig } & \multirow{2}{*}{$\mathrm{t}$} & \multirow{2}{*}{ ضرايب استاندارد } & \multicolumn{2}{|c|}{ ضرايب استاندارد نشده } & \multirow{2}{*}{ متغير } & \multirow{2}{*}{ مدل } & \\
\hline & & & خطا & B & & & \\
\hline $.1+1$ & $-11 / v a$ &.$- / \mathrm{Vg}$ & $\cdot 1 \cdot \Delta$ & $-\cdot / \Delta \Delta$ & حمايت اجتماعى & حمايت اجتماعى & 1 \\
\hline $.1 \cdot 1$ & $-ه / ৭ \&$ & $-\cdot 1 \Delta \varphi$ & $\cdot / \cdot V$ & $-\cdot / 41$ & حمايت اجتماعى & حمايت اجتماعى و & r \\
\hline .1 .1 & $r(\Lambda)$ & 的 & $\cdot / \mathrm{rA}$ & $\cdot / \mathrm{va}$ & كيفيت خواب & كيفيت خواب & I \\
\hline
\end{tabular}

يزوهش حاضر به منظور تعيين ارتباط كيفيت خواب و حمايت اجتماعى ادراى شده با احساس تنهايى در سالمندان مرد انجام

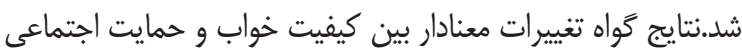
ادراك شده است يعنى هر خه حمايت اجتماعى ادراك شده سالمندان از افراد مهمه، خانواده يا دوستان افزايش مى يابد، كيفيت خواب آنها در همه زيرمقياس ها بهبود مى يابد.اين نتايج با يافته هاى تحقيقات

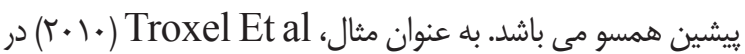
يُروهشى روى سالمندان دجار بى خوابى، به اين نتيجه رسيدند كه هر جه سطح حمايت اجتماعى افراد سالمند افزايش يابد، مشكلات بهات آنها در تاخير در به خواب رفتن كاهش مى يابد و كيفيت خواب آنها بالاتر

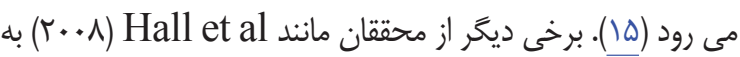

و در نهايت در (جدوله) ملاحظه مى شود كه ضرايب رَرسيونى متغيرهاى ييش بين در هر دو مدل مذكور نيز معنادار

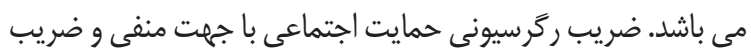
رَر سيونى كيفيت خواب با جهت مثبت وارد معادله مى شوند و نتيجه كرفته مى شود، بين كيفيت خواب و حمايت اجتماعى ادراك شده با احساس تنهايى در مردان سالمند رابطه وجود دارد. اين رابطه به گَونه اى است كه از روى كيفيت خواب و حمايت اجتماعى ادراك شده مى توان به طور معنادارى احساس تنهايى مردان سالمند را ييش

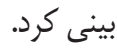


يابد احساس تنهايى افزايش نشان مى دهد.در تبيين عدم معنادارى رابطه زيرمقياس ميزان بازدهى خواب با احساس تنهايیى، با توجه به به تيه هم جهت بودن ضريب همبستخى اين دو متغير با بقيه متغيرها و نزديك بودن آلفا به سطح معنادارى، مى توان اينطور استنباط كرد كه رابطه بين اين دو متغير مانند بقيه زيرمقياس ها وجود دارد، اما حجم نمونه يزوهش حاضر نتوانسته است شرايط را براى معنادار

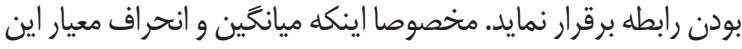
زيرمقياس קإييترين نمره در بين همه زيرمقياسها را دارد كه نشان

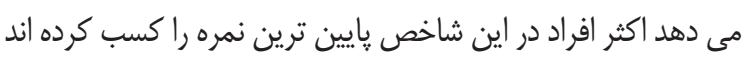

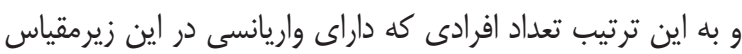
بوده اند كمتر از بقيه زيرمقياس ها بود اند كه موجب نرسيدن تلفآ آلفا به اله سطح معنادارى شده است. اما مابقى زيرمقياس هاى كيفيت خواب

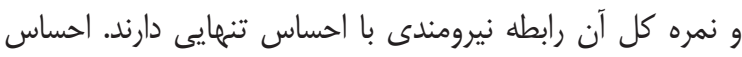
تنهايى خطر بروز اختلال خواب را افزايش داده و منجر به مشكلاتى در تنظيم جرخه خواب و بيدارى فرد مى شود (وج). همانطور كه يافته هاى متعدد نشانكر اين موضوع است كه احساس تنهايى با مشكلات

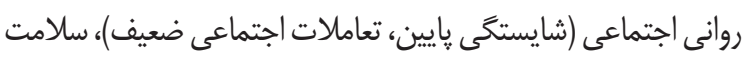
روانى (افسردگى و اضطراب) و سلامت جسمانى (نظير عملكر د ايمنى و مشكلات خواب ) مرتبط است (عبّ). در حالى كه، حمايت اجتماعى جلى إنى مناسب از سالمندان باعث افزايش شادى و احساس كفايت دراست در آنها

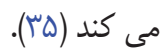

به طور كلى، احساس تنهايى در سالمندان به افزايش هيجان هاى منفى ، فقدان روابط معنادار بين فردى و ادارك منفى نسبت به به خود مى انجامد (عَ). انجام اين يزوهش با محدوديتهايى روبه رو بوده است از جمله،

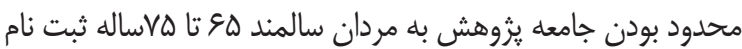
كننده در مراكز جهان ديدًان شهردارى منطقه بيست شهردارى شهر

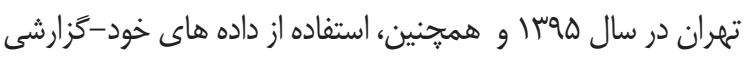
كه نتايج آنها تا حدى متأثر از خوديذيرى اجتماعى است. ييشنهاد

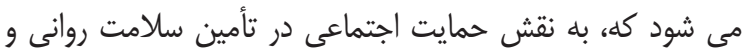

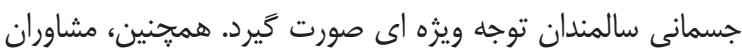

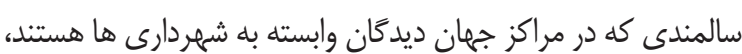
برنامه ها و سخنرانى هايى با محوريت حمايت اجتماعى و ييشخيرى از انزوا در جهت ارتقاى سطح سلامت روانى و جسمانى سالمندان

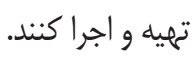

\section{نتيجها كَيرى نهائى}

علل و عوامل روان شناختى و اجتماعى اثركذارى در دوران
طور جزئى ترى به بررسى ارتباط كيفيت خواب و حمايت اجتماعى نواعث

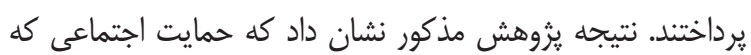
از طريق دوستان تامين شده باشد با كاهش در اختالات خوات التابل

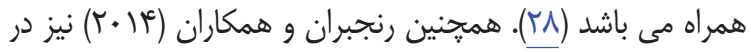

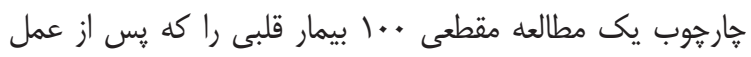
جراحى داراى كيفيت خواب ضعيف بودند مورد بررسى قرار دادند و مشخص شد افرادى كه از حمايتهاى اجتماعى بالاترى برخوردار

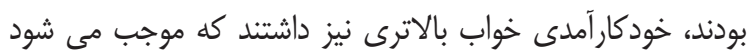

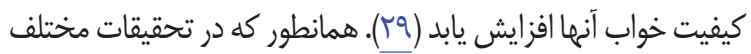
اشاره شد به دلايل مختلف مى توان ادعا كرد كه حمايت اجتماعى براى بهبود كيفيت خواب مناسب است : اول اينكه حمايت اجتماعى إنى

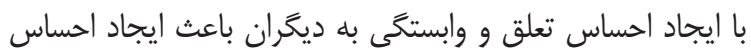

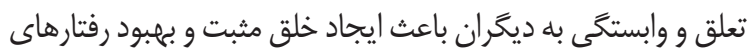
سلامتى شده و در نهايت منجر به ايجاد عادات خواب سالم مى شود. به علاوه احساس اينكه فرد ديخرى وجود دارد يا وجود خواهد داشت، از تنهايى اجتماعى جلوگيرى مى كند. به علاوه حمايت اجتماعى با تنظيم ريتم بيولوزيك در حفظ حالت خواب و بيدارى فرد اثر كذاشته

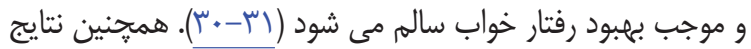
كواه تغييرات معنادار بين حمايت اجتماعى و احساس تنهايى است بدين ترتيب كه هر جه حمايت اجتماعى ادراك شده سالمندان از

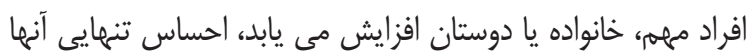
نيز كاهش مى يابد كه با نتايج تحقيقات ييشين همسو مى باشد. بان توجه به اينكه حمايت اجتماعى مجموعه ائ از رفتارهاى حمايتى تئى عمومى و اختصاصى است كه سبب تعديل فشارهاى وارده بر فرد إنى مى شود در نتيجه بر سلامت روانى و جسمانى افراد اثر ميخذارد

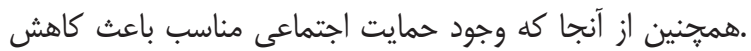

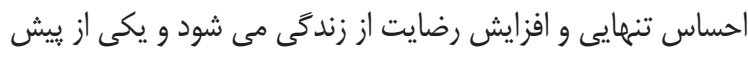
بينى كننده هاى سلامت است بايد تمهيداتى براى افزايش دريافت

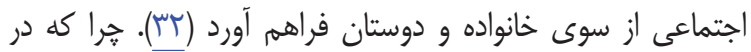

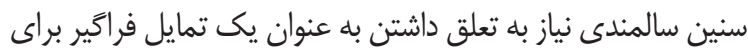

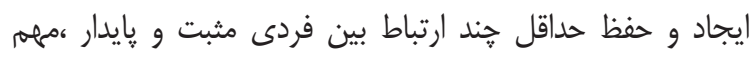

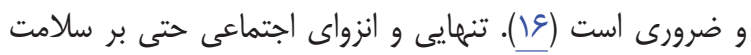

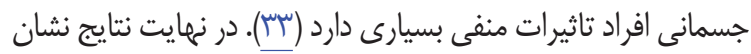
داد كه، تغييرات معنادار بين كيفيت خواب و احساس تنهايى در مردان

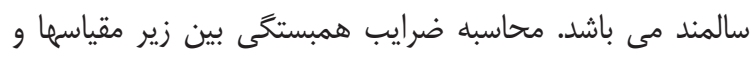

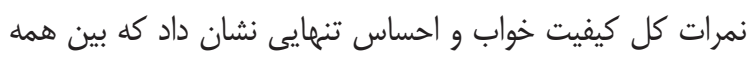
زيرمقياس هاى كيفيت خواب به جز ميزان بازدهى خواب با احساس

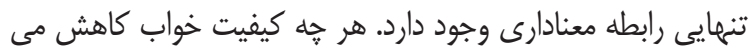




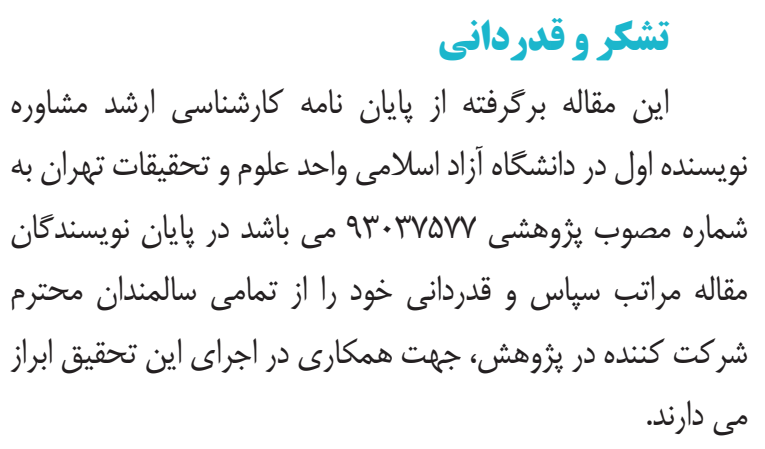

\section{References}

1. World population ageing 2017: highlights, united nation New York, http://www.un.org/en/development/ desa/population/publications/pdf/ ageing/WPA2017_Highlights.pdf.

2. Famil Ahmarian F, khodabakhshi koolaee A, Falsafinejad MA. The effects of group logo-therapy on life expectancy and sleep quality in elderlies of boarding center of Tehran city. Research on Religion \& Health. 2015; 1 (3):11-18. [Persian].

3. Khalili F, Sam SH, Sharifirad GH, Hassanzadeh A, Kazemi M. The Relationship between Perceived Social Support and Social Health of Elderly. HSR.2011; 7 (6): 1216- 1225. [Persian].

4. Izadi Avanji F S, Adib Hajbaghery M, Afazel M R. Quality of sleep and it's related factors in the hospitalized elderly patients of Kashan hospitals in 2007. Feyz. 2009; 12 (4) :52-60. [Persian].

5. Bahrami Einolgasi H, Khodabakhshi koolaee A, Taghvaee D. Efficacy of group physical activity on sleep quality and quality of life among older adults in Kahrizak nursing home. joge. 2016; 1 (1):29-39 URL: http://joge.ir/article-170-fa.html [Persian].

6. Vollrath M, Wicki W, Angst J. The Zurich
سالمندى افراد مطرح مى باشد از جمله؛ مى توان به نقش و ارتباط حمايت اجتماعى در كاهش احساس تنهايى و مشكالات خواب سالمندان اشاره كرد. احساس تنهايى در دوره سالمندى از مولفه هاى روانى - اجتماعى است كه در دوره سالمندى بايد مورد توجه ويزه اي إى

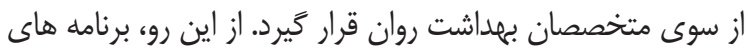

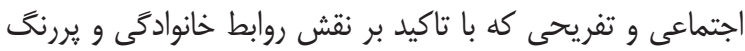

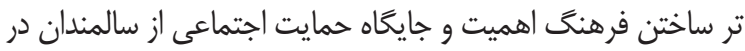
جامعأ ايرانى بسيار ضرورى به نظر مى رسد.

study. VIII. Insomnia: Association with depression, anxiety, somatic syndromes, and course of insomnia. Eur Arch Psychiatry Neurol Sci .1989; 239: 113124. PMID: 2806334.

7. Jacquinet-Salord MC, Lang $\mathrm{T}$, Fouriaud C, Nicoulet I, \& Bingham A. Sleeping tablet consumption, self reported quality of sleep, and working conditions. J Epidemiol Community Health.1993; 47: 64-68. PMID: 8094733 PMCID:PMC1059714.

8. Harrington JJ, Avidan AY. Treatment of sleep disorders in elderly patients. Curr Treat Options Neurol .2005; 7 (5):33952. PMID: 16079039.

9. Taylor DJ, Lichstein KL, Durrence HH. Insomnia as a health risk factor. Behav Sleep Med. 2003; 1 (4): 227-47. doi. org/10.1207/S15402010BSM0104_5.

10. Okuji Y, Matsuura M, Kawasaki N, Kometani S, Shimoyama T, Sato M, et al. Prevalence of insomnia in various psychiatric diagnostic categories. Psychiatry Clin Neurosci. 2002; 56 (3): 239-40. PMID: 12047575. DOI: 10.1046/j.1440-1819.2002.01012.x.

11. Rambod M, Ghodsbin F, Beheshtipour N, Raieyatpishe AA, Mohebi Noubandegani Z, Mohammadi-Nezhad A. The Relationship between Perceived 
Social Support and Quality of Sleep in Nursing Students. IJN. 2012; 25 (79): 12-23.[Persian].

12. Sadegh-Moghadam L, Delshad Noghabi A, Farhadi A, Nazari SH, Eshghizade M, Chopanvafa F, Niazi Evari M. Life Satisfaction in older adults: Role of Perceived Social Support .Jsums.2016; 22 (6):1043- 1051. [Persian].

13. Nakahara J. Effects of social activities outside the home on life satisfaction among elderly people living alone .International Journal of Psychological Studies. 2013;5(1):112. doi.org/10.5539/ ijps.v5n1p112.

14. Abu-Bader S.H, A R, A.S B. Predictors of life satisfaction in frail elderly. Journal of Gerontological Social Work. 2003; 38 (3):3-7. doi.org/10.1300/ J083v38n03_02.

15. Troxel WM, Buysse D J, Monk T H, Begley A, Hall M. Does social support differentially affect sleep in older adults with versus without insomnia? J Psychosom Res 2010; 69: 459-466. PMID: 20955865 PMCID: PMC2958100 DOI:10.1016/j.jpsychores.2010.04.003.

16. Hojati H, SharifNia S, Hosseinali Pur S, NikKhah F, Asayesh H. The Effect of Reminiscence Groups on Loneliness and the Need for Belonging in Elders. 3. 2011; 13 (1) : 46-52. [Persian].

17. Laalifaz A,Asgari AA. The power of predicting perceived parenting styles and demographic variables on girl student's loneliness feeling. Jfmh.2008; 10 (37): 71-78. DOI: 10.22038/jfmh.2008.1778.

18. Bahirayi H, Delavar A, Ahadi H. Standardization of UCLA Loneliness Scale (version 3) on Students Attending
Universities in Tehran. Applied Psychology. 2006; 1 (1): 6-18. [Persian]. 19. Heravi Karimloo M, Anoosheh M, Foroughan M, Sheykhi M T, Hajizade E, Seyed Bagher Maddah M S, et al . Loneliness From the Perspectives of Elderly People: A Phenomenological Study. Salmand. 2008; 2 (4): 410-420. [Persian].

20. Cacioppo J T, Cacioppo S. Social Relationships and Health: The Toxic Effects of Perceived Social Isolation. Soc Personal Psychol Compass.2014; 8 (2): 58-72. DOI: 10.1111/spc3.12087.

21. Seyedian M, Falah M, Nourouziyan M , Nejat S, Delavar A, Ghasemzadeh H. validity of the Farsi version of MiniMental State Examination. Medical Council Of I.R.I.2008 ; 25 (4): 408-414. [Persian].

22. Madadi M, Khodabakhshi Koolaee A. Efficacy of Kataria Group Laughter Therapy and Physical Activity on Hope and Meaningfulness in Life among Elderlies in Tehran. 3. 2016; 2 (4) :4048. DOI:10.21859/ijrn-02046. [Persian].

23. Safa A, Adib-Hajbaghery M, FazelDarbandi A. The relationship between sleep quality and quality of life in older adults. IJPN. 2015; 3 (3) :53-62. [Persian].

24. Beyrami M, Alizadeh Goradel J, Ansarhosein S, Ghahraman Moharrampour N. Comparing Sleep Quality and General Health Among the Elderly Living at Home and at Nursing Home. Salmand. 2014; 8 (4) :47-55. [Persian].

25. Khodabakhshi-Koolaee A, MirAfzal N. Relationship between Humor and Social 
Support with Sex Satisfaction in Elderly Married Women. joge. 2017; 2 (1): 1-10URL: http://joge.ir/article-1-141-fa. html [Persian].

26. Hardan - Khalil KH, Mayo A M. Psychometric Properties of the Multidimensional Scale of Perceived Social Support. Clinical Nurse Specialist. 2015;29(5):258-261.DOI:10.1097/ NUR.0000000000000148.

27. Sodani M, Neysi A, SHogaeyan M, Neysi A. The effect of group logo - therapy on loneliness in retired men. Researches of Cognitive and Behavioral Sciences. 2012; 2 (1): 43-54. [Persian].

28. Hall M, Buysse DJ, Nofzinger EA, Reynolds CF, Thompson W, Mazumdar S, et al. Financial strain is a significant correlate of sleep continuity disturbances in late-life. Biol Psychol 2008; 77: 217-222. PMID: 18055094 PMCID:PMC2267650 DOI: 10.1016/j. biopsycho.2007.10.012.

29. Ranjbaran S, Dehdari T, Mahmoodi Majdabadi M, Sadeghniiat-Haghighi K. The survey of sleep self-efficacy and perceived social support status in patients with poor sleep quality after coronary artery bypass surgery. RJMS. 2014; 21 (126) :33-42. [Persian].

30. Akerstedt T, Fredlund P, Gillberg M, Jansson B. Work load and work hours in relation to disturbed sleep and fatigue in a large representative sample. J Psychosom Res.2002; 53: 585-588. PMID: 12127175.

31. Morin CM, Rodrigue S, Ivers H. Role of stress, arousal, and coping skills in primary insomnia. Psychosom Med .2003; 65: 259-267. PMID:12651993.
32. Taei Z, Radfar M, MogadamTabriz F, Sheikhei N. THE EFFECT OF DIMENSION OF SOCIAL SUPPORT ON HOPE AND LONELINESS IN PATIENTS WITH BREAST CANCER. J Urmia Nurs Midwifery Fac. 2015; 13 (6) :473-480. [Persian].

33. Courtin E \& Knapp M. (2015) Social isolation, loneliness and health in old age: a scoping review. Health and Social Care in the Community Dec 28. doi: 10.1111/hsc. 12311 .

34. Hemmati Alamdarlou G, Dehshiri G, Shojaie S, Hakimi Rad E. Health and Loneliness Status of the Elderly Living in Nursing Homes Versus Those Living with Their Families . Salmand. 2008; 3 (2): 557-564. [Persian].

35. Khodaabakhshi-Koolaee A, Nasiri Z. Compare Self-Esteem and Social Support among Ageing. Zahedan Journal Research Medicine Science 2012; 14 (9): 101-103.

36. Kitzmüller G, Clancy A, Vaismoradi M, Wegener CH, Bondas T. "Trapped in an Empty Waiting Room"-The Existential Human Core of Loneliness in Old Age: A Meta-Synthesis. Qualitative health Research, 2018; 28 (2):213-230. https:// doi.org/10.1177/1049732317735079. 